\title{
Prevalence and Predictors of Malaria Among HIV Infected Subjects Attending an Antiretroviral Therapy (ART) Clinic in a Tertiary Healthcare Facility in Central Nigeria
}

\section{Yahaya}

Department of Microbiology, Nasarawa State University Keffi, Nasarawa State, Nigeria

\author{
V. B. Oti (Corresponding Author) \\ Department of Microbiology, Nasarawa State University Keffi, Nasarawa State, Nigeria \\ Email: Obabavictor1@gmail.com
}

\section{J. Y. Dahiru}

Department of Biological Sciences, Federal University Kashere, Gombe State, Nigeria

\author{
Article History \\ Received: January 16, 2020 \\ Revised: February 9, 2020 \\ Accepted: February 17, 2020 \\ Published: February 20, 2020 \\ Copyright (C) 2020 ARPG \& \\ Author \\ This work is licensed under \\ the Creative Commons \\ Attribution International \\ (c) $(1)$ \\ CC BY: Creative \\ Commons Attribution \\ License 4.0
}

\begin{abstract}
Malaria is still considered globally as a leading cause of morbidity with Nigeria carrying the highest burden of $19 \%$. Coinfection of malaria and Human Immunodeficiency Virus (HIV) accelerate disease progression of HIV/AIDS subjects. This study investigated the prevalence and predictors of malaria among HIV infected subjects attending the antiretroviral therapy Clinic at Federal the Medical Centre, Keffi, Nigeria. After ethical clearance, 200 whole blood specimens were collected from patients who gave informed consent and completed a self-structured questionnaire. The specimens were examined for malarial parasite using rapid kits and microscopy. The overall prevalence of the infection was 78/200 (39.0\%). The prevalence was higher in male (44.7\%) than female (34.0\%) subjects. Those subjects aged < 20 years (54.5), male gender (44.7\%), non-formal education holders (61.5\%), farmers $(62.5 \%)$, stream water users (48.1\%), those that lives in rural setting (43.6\%), those that do not use Insecticides Treated Nets (ITNs) (39.4\%) and swampy environment dwellers (41.7\%) were identified predictors for malaria infection in the area. All the predictors studied did not show any statistically significant difference with the infection but some arithmetic difference exists $(\mathrm{P}>0.05)$. The $39.0 \%$ prevalence of malaria in HIV infected subjects is a public health concern. Therefore, Public health surveillance and health education among HIV population should be advocated to help eradicate malaria comes 2030. Further study that will characterize the genes of the parasite should be carried out.
\end{abstract}

Keywords: Malaria; Plasmodium species; HIV; Prevalence; Subjects; Central Nigeria.

\section{Introduction}

Malarial and Human Immunodeficiency Virus (HIV) infections are public health issues facing Africa in recent years and coinfection of these two infections has scantly been studied [1-3]. Our current understanding of human immune response to malaria and HIV leads us to expect of the other [4]. Many other types of infections have been documented to cause at least a transient increase in HIV viral load [5, 6]. There were 435, 000 deaths from malaria globally in 2017 compared with 451, 000 estimated deaths in 2016 [7], 88\% of such deaths occurring in WHO African region [7]. Currently, there are almost 37.9 million people living with HIV, and tens of millions mortality have been reported due to AIDS-related causes since the beginning of the epidemic [8]. Those who are at high risk are young children, pregnant women and immunocompromised people (PLWHIV) [7, 9].

In Nigeria, where the malaria situation has improved, almost 60 million people (about $50 \%$ of the population) experience one episode of malaria or the other during the year and the disease causes death of over 200,000 people annually $[10,11]$. Hence, it is logical to expect malaria to do the same; and thus accelerate HIV disease progression. Malaria is a mosquito-borne infectious disease of humans and other animals caused by Plasmodium species [11]. The disease arises from the division of Plasmodium parasites in the red blood cells, causing symptoms which headache and fever, in severe cases progressing to coma and/or death. It is widespread in tropical and subtropical regions, including much of Sub-Saharan Africa, Asia, and the Americas [11-13]. Five species of malarial parasite causes infection in humans exists [14]. Severe disease is largely caused by Plasmodium falciparum while the disease caused by Plasmodium vivax, Plasmodium ovale and Plasmodium malariae is generally mild and seldom fatal [14, 15]. This infection still remains a life threatening vector borne concern and has a significant role on the economic development of most endemic countries [13, 16, 17].

Malaria transmission can be mitigated by preventing mosquito bites by distribution of insecticidal treated net (ITN) insect repellants, or by mosquito-control measures such as spraying insecticides and draining stagnant water [5]. There is no vaccine that offers a high level of protection in existence but efforts in developing such are ongoing. Although number of medications are available as prophylaxis especially among travelers to malaria-endemic regions [3]. 
Co-infection of malaria with HIV is very common in Sub-Saharan Africa [1, 5, 6, 10, 14, 18-20]. The overlapping features of malaria and HIV/AIDS has established the fact that people living with HIV/AIDS are at high risk of clinical malaria and HIV infection can reduce the protection offered by anti-malarial drugs [4, 21]. Malaria contributes to a temporary increase in viral load among HIV- infected people which may lead to increased clinical disease and enhances mother to child transmission [22, 23]. This study examined the prevalence and predictors of malaria among HIV infected subjects attending ART clinic in a tertiary healthcare facility in Central Nigeria.

\section{Materials and Methods}

\subsection{Study Area}

This study was carried out in Keffi. Keffi is $68 \mathrm{Km}$ from Abuja, the Federal Capital Territory and $128 \mathrm{Km}$ from Lafia, Nasarawa State. It lies in latitude eight $5^{\prime} \mathrm{N}$ of the equator and longitude seven 8 ' $\mathrm{E}$, it also situates on altitude of $850 \mathrm{M}$ above sea level [24]. The average annual rainfall in Keffi is $\pm 2,000$ millimeters (79 in), and is often heavier during the rainy months having its peak around July through September [25]. Most of the people living here are dominantly traders, farmers, civil servants, and students.

\subsection{Study Population}

A prospective cross sectional study was carried out among $200 \mathrm{HIV}$ infected subjects attending the facility who agreed to participate in the study from a period of June through August, 2018. Structured questionnaire was administered to the parents/guardians of the children; information on age, gender and risk factors such as; source of drinking water and use of insecticidal treated nets was obtained from each participant. Participants who could not read or write in the English Language were interviewed orally in Hausa. Representative sample size was determined using the formula propounded by Swinscow and Campbell [26].

\subsection{Sample Collection}

Blood sample was collected from each participant by venipuncture. A tourniquet was used to tie in the upper region of the arm for the veins to be visible and also increase the pressure of blood into the veins. The area in which needle was inserted was cleaned with a spirit cotton wool after which the needle was introduced into the vein, and $5 \mathrm{ml}$ of blood was collected. The tourniquet was loosed before the needle was pulled out from the vein and the blood transferred to an EDTA (Ethylenediamine Tetra Acetic Acid) container after which it was labeled accordingly using unique identifier codes to ensure confidentiality of participants [13].

\subsection{Laboratory Analysis}

\subsubsection{Rapid Diagnosis of Malaria Parasite}

All the subjects were screened for malarial parasite using the Care Start ${ }^{\mathrm{TM}}$ malaria HRP2 (Pf) rapid test for Plasmodium falciparum malaria ML no: 338 (Orchid Biomedical System, India) following the manufacturer's specifications prior to microscopy.

\subsubsection{Microscopic Examination of the Malaria Parasite}

Thin and thick smears were prepared to determine the malaria parasitemia in the target population of HIV subjects. The both smears were stained using 3\% Giemsa technique as described by Cheesbrough [27]. This is considered as the gold standard and it was used to confirm the initial screening with the rapid kit.

\subsection{Ethical Clearance}

In line with the Helsinki Declaration which specifies the code of ethics for biomedical research involving human samples, clearance for the study was obtained from the Ethical Committee on Health Research of Federal Medical Centre, Keffi, Nigeria. Formal consents were retrieved from all participating subjects using a consent form.

\subsection{Statistical Analysis}

The information obtained were analyzed statistically using Smith's Statistical Package (SSP version 2.80, Claremont, California-USA). Chi-square statistical test was used to determine association and values obtained were considered statistically significant at $\mathrm{p} \leq 0.05$.

\section{Results and Discussion}

Out of $200 \mathrm{HIV}$ subjects examined for the parasitic infection, $78(39.0 \%)$ were infected with malarial parasite. Table 1 shows the prevalence of malaria among HIV infected subjects with respect to possible predictors. The prevalence of malaria in this study was higher among those $<20$ years of age $(54.5 \%)$, male gender $(44.7 \%)$, nonformal education holders $(61.5 \%)$, farmers $(62.5 \%)$, stream water users $(48.1 \%)$, those that lives in rural setting (43.6\%), those that do not use ITNs (39.4\%) and swampy environment dwellers (41.7\%). All of the studied predictors showed no statistically significant association with malaria but some arithmetic differences were observed $(\mathrm{p}>0.05)$. 
Table-1. Prevalence of malaria among HIV infected subjects attending Federal Medical Centre Keffi, Nigeria with respect to possible predictors

\begin{tabular}{|c|c|c|c|c|c|}
\hline Parameters & No. Examined & No. Positive & Prevalence $(\%)$ & $x^{2}$ & $P$ \\
\hline $\begin{array}{l}\text { Age (Years) } \\
<20 \\
21-30 \\
31-40 \\
>40\end{array}$ & $\begin{array}{l}22 \\
54 \\
86 \\
38\end{array}$ & $\begin{array}{l}12 \\
20 \\
34 \\
12\end{array}$ & $\begin{array}{l}54.5 \\
37.0 \\
39.5 \\
31.6\end{array}$ & 1.3334 & 0.7212 \\
\hline $\begin{array}{l}\text { Gender } \\
\text { Male } \\
\text { Female }\end{array}$ & $\begin{array}{l}94 \\
106\end{array}$ & $\begin{array}{l}42 \\
36\end{array}$ & $\begin{array}{l}44.7 \\
34.0\end{array}$ & 1.0525 & 0.3049 \\
\hline $\begin{array}{l}\text { Educational Status } \\
\text { Non-formal education } \\
\text { Primary } \\
\text { Secondary } \\
\text { Tertiary }\end{array}$ & $\begin{array}{l}26 \\
34 \\
62 \\
78\end{array}$ & $\begin{array}{l}16 \\
18 \\
20 \\
24\end{array}$ & $\begin{array}{l}61.5 \\
52.9 \\
32.3 \\
30.8\end{array}$ & 4.7868 & 0.1880 \\
\hline $\begin{array}{l}\text { Occupation } \\
\text { Artisans } \\
\text { Students } \\
\text { Civil servants } \\
\text { Farmers }\end{array}$ & $\begin{array}{l}36 \\
54 \\
78 \\
32\end{array}$ & $\begin{array}{l}16 \\
20 \\
22 \\
20\end{array}$ & $\begin{array}{l}44.4 \\
37.0 \\
28.2 \\
62.5\end{array}$ & 4.8347 & 0.1842 \\
\hline $\begin{array}{l}\text { Locality } \\
\text { Rural } \\
\text { Urban }\end{array}$ & $\begin{array}{l}78 \\
122 \\
\end{array}$ & $\begin{array}{l}34 \\
44 \\
\end{array}$ & $\begin{array}{l}43.6 \\
36.1 \\
\end{array}$ & 0.4914 & 0.4833 \\
\hline $\begin{array}{l}\text { Sources of Drinking } \\
\text { Water } \\
\text { Tap } \\
\text { Well } \\
\text { Stream }\end{array}$ & $\begin{array}{l}84 \\
62 \\
54\end{array}$ & $\begin{array}{l}24 \\
28 \\
26\end{array}$ & $\begin{array}{l}28.6 \\
45.2 \\
48.1\end{array}$ & 3.0198 & 0.2208 \\
\hline $\begin{array}{l}\text { Use of ITNs } \\
\text { Yes } \\
\text { No }\end{array}$ & $\begin{array}{l}134 \\
66 \\
\end{array}$ & $\begin{array}{l}52 \\
26 \\
\end{array}$ & $\begin{array}{l}38.8 \\
39.4 \\
\end{array}$ & 0.0028 & 0.9577 \\
\hline $\begin{array}{l}\text { Nature of Environment } \\
\text { Swampy } \\
\text { Dry }\end{array}$ & $\begin{array}{l}24 \\
176\end{array}$ & $\begin{array}{l}10 \\
68\end{array}$ & $\begin{array}{l}41.7 \\
38.6\end{array}$ & 0.0352 & 0.8512 \\
\hline
\end{tabular}

Human immunodeficiency virus infected individuals are at higher risk of malaria and other opportunistic infections because of their compromised immune systems. Sub-Saharan Africa carries a high burden of coinfection with malaria and HIV $[2,7,16]$.

An overall prevalence rate of $39.0 \%$ was recorded among the HIV subjects attending the Federal Medical Centre, Keffi, Nigeria in this study which is in agreement with the reports in other parts of the country. It was $65 \%$ among people living with HIV/AIDS in Keffi Bello and Ishaleku [1], 56.8\% among patients in Keffi Yohanna, et al. [13], 24\% among HIV patients in Jos Iroezindu, et al. [28], 14.2\% among HIV patients in Uyo Amadi, et al. [29], $16.2 \%$ among HIV-infected individuals in North Central Nigeria Inyama, et al. [15], 59.2\% among HIV patients in Kaduna Abioye, et al. [5] and 18.5\% among HIV positive individuals in Osogbo Olusola, et al. [3]. Findings from other countries have been reported such as 14\% among HIV seropositive patients in Cameroon Sandie, et al. [19], 61.7\% among HIV patients in Mozambiqu Saracino, et al. [20], 36\% in South Africa Cohen, et al. [18], 83.8\% among HIV infected and uninfected population in Uganda Katrak, et al. [6] and a high malaria parasite density among HIV/AIDS subjects in Kenya Kirinyet [30]. Differences in sample size, study population, sensitivity and specificity of tests used, weather and climate conditions may account for these differences in the prevalence rates.

In this study, there was no statistically significant association between the age groups and malaria $(p>0.05)$. The infection was highest among subjects aged $<20$ years $(54.5 \%)$ and least prevalence among those aged greater than 40 years old (31.6\%). This correlates with the findings of Bello and Ishaleku [1] in Keffi, Amadi, et al. [29] and Kirinyet [30] reported that age was not significant to malaria acquisition in their studies. The less than 20 years subjects are active with developing immune system and have less knowledge on how to prevent the infection which enhance their vulnerability to the infection.

With respect to gender, malaria was not associated with gender of the subjects $(p>0.05)$. The infection was higher in male $(44.7 \%)$ than the female $(34.0 \%)$ counterparts. Similar studies in Nigeria and beyond also report same outcome [9, 11, 30] but contradicts the reports of Sandie, et al. [19] in Cameroun, Bello and Ishaleku [1] in Keffi, and Amadi, et al. [29] in Uyo, Nigeria. Male gender tends to have severe immunosuppression than the female counterparts. This finding might be because males often stayed out lately at night most times and thus exposes themselves to mosquito bites.

There was no statistically significant association between educational status and the prevalence of malaria $(p>$ 0.05). Those subjects without any formal education reported the highest prevalence of $61.5 \%$ while those with a tertiary education had the least prevalence of $30.8 \%$. This outcome is obvious because education has long been 
embraced to be of great advantage in our society. Therefore, more improved preventive measures and prophylaxis is intertwined with higher levels of education.

This study reports showed that the prevalence of malaria is highest among farmers $(62.5 \%)$ and lowest among the civil servants $(28.2 \%)$. There was no statistical association between the parasitic infection and occupation of the subjects in the area $(\mathrm{P}>0.05)$. Malaria is understood to be both a disease of poverty and a cause of poverty [5]. The high prevalence rate among farmers might be because of low income rate, lack of proper preventive means and treatment and also lack of proper feeding which make their body system vulnerable to opportunistic infections including malaria.

In this study, no significant association statistically was observed between malaria and the locality of the subjects $(\mathrm{p}>0.05)$. The prevalence of the infection was higher among subjects from the rural areas $(43.6 \%)$ than those in the urban settings $(36.1 \%)$. This report is in consonance with Iroezindu, et al. [28] findings in Jos, Nigeria. Rural dwellers are more likely to indulge in practices that create favorable breeding environment for the vector. Furthermore, malaria prevention and control programs are less commonly done in rural settings in Nigeria.

In this study, no significant association statistically was observed among malaria and use of ITNs $(p>0.05)$. The prevalence of the infection was higher among those subjects that do not use ITNs (39.4\%) than those who use ITNs $(38.8 \%)$. Findings in this study was also recorded in related researches in Nigeria and other countries [13, 3133]. The protective effect of ITNs usage shown in this study adds to the body of evidence supporting the effectiveness of ITNs for protection against malaria and other vector-borne diseases [7]. This finding is a wake-up call to all healthcare providers to provide and continue distributing the long lasting ITNs to HIV population in Nigeria

Source of drinking water and nature of environment are not statistically associated with malaria infection among the population ( $\mathrm{P}>0.05$ ). Amadi, et al. [29] and Iroezindu, et al. [28] reported similar findings in their studies. Those that use stream water and live in swampy environment are at high risk of malaria from this study. This high rate of stream water users and those in swampy environment is interrelated. HIV individuals living in riverine areas are at high risk of malaria infection.

\section{Conclusion}

This study successfully revealed a high prevalence of malaria among HIV infected subjects in the area. None of the predictors studied showed any statistically significant association with the infection $(\mathrm{p}>0.05)$. This study has contributed to the understanding of malaria among HIV subjects in Nigeria. Thus, continuous screening of malaria parasites in HIV patients and public health awareness should be priorities in eliminating the infection in Nasarawa State, Nigeria.

\section{Acknowledgement}

We thank the staff and study subjects of the facility for their support in making this study a success. This study did not acquire any specific grant from funding agencies in the public, commercial, or not-for-profit sectors. We dedicate this study to the blessed memory of Patrick Baba Oti, PhD.

\section{References}

[1] Bello, B. and Ishaleku, D., 2018. "Prevalence of malaria infection among people living with hiv/aids at federal medical center keffi (Nasarawa state), Nigeria." Journal of Advances in Microbiology, vol. 11, pp. $1-6$.

[2] Carlucci, J. G., Blevins, P. M., Cherry, C. B., Lopez, M. L., Green, A. F., Gonzalez-Calvo, L., Moon, T. D., and Ogumaniha-SCIP, Z. C., 2017. "Prevalence and determinants of malaria among children in Zambezia Province, Mozambique." Malaria Journal, vol. 16, p. 108.

[3] Olusola, O., Oluwatoyin, A. O., Oyebode, A. T. A., Sunday, S. T., Taiwo, A. O., Adekunle, O. O., Oluyinka, O. O., and Oluwaseyi, A. A., 2014. "Prevalence of Plasmodium falciparum parasiteamia and its correlation with heamatological parameters among HIV-positive individuals in Nigeria." Journal of Tropical Medicine, pp. 1-6.

[4] Akyala, I. A., Amuta, E. U., Abiodun, P., and Agieni, A. G., 2012. "Malaria parasitemia among seropositive drug naïve and drug experience HIV patients attending Federal Medical Centre, Keffi, Nasarawa State-Nigeria." International Journal of Microbiology and Immunology Research, vol. 1, pp. 006-009.

[5] Abioye, J. O. K., Abdullahi, D. K., and Ako, A. A., 2014. "Prevalence of malaria among HIV patients in 44 Nigeria army reference hospital Kaduna (44 NARHK)." International Journal of Advanced Biological Research, vol. 4, pp. 412-415.

[6] Katrak, S., Day, N., Ssemmondo, E., Kwarisiima, D., Midekisa, A., Greenhouse, B., Kamya, M., Havlir, D., and Dorsey, G., 2016. "Community-wide prevalence of malaria parasitemia in HIV-infected and uninfected populations in a high-transmission setting in Uganda." The Journal of Infectious Diseases, vol. 213, pp. 1971-1978.

[7] World Health Organization, 2018. "World Malaria Report 2018: Global malaria programme, WHO, Geneva."

[8] UNAIDS, 2019. "2019 global aids update: Communities at the centre; july 2019. Unaids. Aids info website; accessed july 2019." Available: http://aidsinfo.unaids.org 
[9] Olasunkanmi, O. I., Akingbade, O. A., Akinjinmi, A. A., Okerentugba, P. O., Onajobi, I. B., and Okonko, I. O., 2013. "Prevalence of malaria Plasmodium among children in Abeokuta, Nigeria." Academia Arena, vol. 5, pp. 44-47.

[10] Marete, I. K., Mutugi, M., Lagat, Z., Obala, A., Simba, J., Mwangi, A., and Esamai, F., 2014. "Malaria parasitaemia among febrile children infected with human immunodeficiency virus in the context of prophylactic cotrimoxazole as standard of care: A cross-sectional survey in Western Kenya." East African Medical Journal, vol. 91, pp. 21-27.

[11] Okokon, I. I., Ubong, A. U., Kenneth, O. I., and Anthony, A. I., 2017. "Climate and Plasmodium falciparum infection on the Jos Plateau, Nigeria." International Journal of Microbiology and Biotechnology, vol. 2, pp. 161-165.

[12] Ukoroije, B. R. and Abowei, J. F. N., 2012. "Some occupational diseases in culture fisheries management and practices part one: malaria and river blindness (Onchocerciasis)." International Journal of Fishes and Aquatic Sciences., vol. 1, pp. 47-63.

[13] Yohanna, J., Oti, V., Amuta, E., Philip, A., and Anizoba, L., 2019. "Plasmodium falciparum infection among febrile patients attending a tertiary healthcare facility in central Nigeria: Prevalence, haematologic and sociodemographic factors." International Journal of Tropical Diseases, vol. 2, pp. 1-6.

[14] Bate, A., Kimbi, H. K., Lum, E., Lehman, L. G., Onvoh, E. F., Ndip, L. M., Niabi, C. M., Tonga, C., Wempnje, B. G., et al., 2016. "Malaria infection and anaemia in HIV-infected children in Mutengene, Southwest Cameroun: a cross sectional study." BMC Infectious Diseases, vol. 16, p. 523.

[15] Inyama, P. U., Omalu, I. C. J., Anyanwu, G. I., Ideniyi, K. A., and Pam, D. D., 2016. "Plasmodium falciparum and Plasmodium malariae among HIV-infected individuals in North-Central Nigeria." International Journal of Applied Biological Research, vol. 7, pp. 27-36.

[16] Kwenti, T. E., Edo, E., Ayuk, B. S., and Kwenti, T. D. B., 2017. "Prevalence of coinfection with malaria and HIV among children in Yaoundé, Cameroun: a cross-sectional survey performed in three communities in Yaoundé." Yangtze Medicine, vol. 1, pp. 178-188.

[17] Okwelogu, I. S., Ikpee, O. O., and Aribodor, D. N., 2012. "Evaluation of knowledge, attitude and practice and pregnant women on malaria, intermittent preventive treatment and long lasting insecticidal nets in Ihiala Local Government Area of Anambra State, Nigeria." Nigerian Journal of Parasitology, vol. 33, pp. 9-14.

[18] Cohen, C., Karstaedt, A., Frean, J., Thomas, J., Govender, N., and Prentice, E., 2005. "Increased prevalence of severe malaria in HIV infected adults in South Africa." Clinical Infectious Disease, vol. 41, pp. 16311637.

[19] Sandie, S. M., Sumbele, I. U. N., Tasah, M. M., and Kimbi, H. K., 2019. "Malaria parasite prevalence and haematological parameters in HIV seropositive patients attending the regional Hospital Limbe, Cameroon: a hospital-based cross-sectional study." BMC Infectious Diseases, vol. 9, p. 988.

[20] Saracino, A., Nacarapa, E. A., Massinga, E. A. C., Martinelli, D., Scacchetti, M., and , O. C., 2012. "Prevalence and clinical features of HIV and malaria co-infection in hospitalized adults in Beira, Mozambique." Malaria Journal, vol. 11, pp. 1-8.

[21] Amuta, E. U., Houmsou, R. S., and Sdiya, A. W., 2012. "Malarial infection among hiv patients on antiretroviral therapy (art) and those not on art. A case study of federal medical centre, makurdi, Benue state, Nigeria." Nigeria Journal of Parasitology, vol. 33, pp. 59-62.

[22] Corbett, E. L., 2012. "AIDS in Africa III: HIV-1/AIDS and the control of other infectious diseases in Africa." The Lancet., vol. 359, pp. 2177-2187.

[23] Miguel-Oteo, M., Jiram, A. I., Ta-Tang, T. H., Lanz, M., Hisam, S., and Rubio, J. M., 2017. "Nested multiplex PCR for identification and detection of human Plasmodium species including Plasmodium knowlesi." Asian Pacific Journal of Tropical Medicine, vol. 10, pp. 299-304.

[24] Akwa, V. L., Binbol, N. L., Samaila, K. L., and Marcus, N. D., 2007. Geographical perspective of Nasarawa state. Keffi: Onaivi printing and Publishing company. p. 3.

[25] Binbol, N. L. and Marcus, N. D., 2010. "Geography of Nasarawa State: A study of flora and fauna." pp. 18.

[26] Swinscow, T. D. V. and Campbell, M. J., 2002. Statistics at Square. 10th ed. London: BMJ Books.

[27] Cheesbrough, M., 2010. District laboratory practice in tropical countries. Low price ed. Publisher Cambridge University Press, pp. 240-241.

[28] Iroezindu, M. O., Agaba, E. I., Okeke, E. N., Daniyam, C. A., Obaseki, D. O., Isa, S. E., and Idoko, J. A., 2012. "Prevalence of malaria parasitaemia in adult HIV- infected patients in Jos, North-Central Nigeria." Nigerian Journal of Medicine, vol. 21, pp. 209-213.

[29] Amadi, C. P., Ikon, G. M., and Inyang, U. C., 2018. "Current prevalence of falciparum malarial infection among HIV patients on highly active antiretroviral therapy in University of Uyo teaching Hospital, Uyo, Nigeria." International Journal of Research in Medical Sciences, vol. 6, pp. 2916-2922.

[30] Kirinyet, J. K., 2019. "An assessment of malaria parasite density among HIV/AIDS subjects at different levels of CD4 T-cells prior to antimalarial therapy at Chulaimbo Sub-County Hospital, Western Kenya." Journal of Tropical Medicine, Available: https://www.ncbi.nlm.nih.gov/pubmed/31354844

[31] Aschale, Y., Mengist, A., Bitew, A., Kassie, B., and Talie, A., 2018. "Prevalence of malaria and associated risk factors among asymptomatic migrant laborers in West Armachiho District, Northwest Ethiopia." Research and Reports in Tropical Medicine, vol. 9, pp. 95-101. 
[32] Martinez-Perez, G., Lansana, D. P., Omeonga, S., Gupta, H., Breeze-Barry, B., Gonzalez, R., Bardaji, A., Sarukhan, A., Goteh, J. D. K., et al., 2018. "Prevalence of Plasmodium falciparum infection among pregnant women at first antenatal visit in post-Ebola Monrovia, Liberia." Malaria Journal, vol. 17, p. 357.

[33] Oladele, O. V., Onuoha, S. C., Hamafyelto, H. S., Onisope, O., Fauziyya, A., Akindigh, M., Abdullahi, T., Ilu, M. L., and Ikeh, E., 2018. "Prevalence of malaria infection among patients attending Murtala Mohammed specialist hospital Kano, Nigeria." African Journal of Clinical and Experimental Microbiology, vol. 9, pp. 214-220. 